\title{
Antioxidant Active Principles Isolated from Psidium guajava Grown in Thailand
}

\section{Suganya Tachakittirungrod ${ }^{1}$, Fumio Ikegami $^{2}$, and Siriporn Okonogi ${ }^{1 *}$}

\author{
${ }^{1}$ Faculty of Pharmacy, Chiang Mai University, Chiang Mai, 50200, Thailand \\ ${ }^{2}$ Center for Environment, Health and Field Sciences, Chiba University, Japan
}

\begin{abstract}
Antioxidant active compounds were isolated from methanol crude extracts of the leaves of Guava (Psidium guajava L.) grown in Thailand. The isolated compounds were screened for their in vitro antioxidant activity by a DPPH free radical scavenging assay. Results indicate that three isolated compounds contribute importantly to the antioxidant activity of guava leaves, providing a scientific basis for the use of this plant in traditional medicine. Their structures were determined on the basis of spectroscopic and chemical methods. The most active compound was found to be quercetin along with two flavonoid compounds, quercetin-3-O-glucopyranoside and morin. The isolated quercetin, quercetin-3-O-glucopyranoside and morin showed significant scavenging activity with $\mathrm{IC}_{50}$ of $1.20 \pm 0.02,3.58 \pm 0.05$ and $5.41 \pm 0.20 \mu \mathrm{g} / \mathrm{ml}$, respectively.
\end{abstract}




\section{Keywords}

Guava, Psidium guajava, Flavonoid, Antioxidant activity

\section{Introduction}

Free radicals are produced in normal and/or pathological cell metabolism. Oxidation is essential to many living organisms for the production of energy to fuel biological processes. However, the uncontrolled production of oxygen derived free radicals is involved in the onset of many diseases such as cancer, rheumatoid arthritis, cirrhosis and arteriosclerosis as well as in degenerative processes associated with aging. Exogenous chemical and endogenous metabolic processes in the human body or in the food system might produce highly reactive free radicals, especially oxygen derived radicals, which are capable of oxidizing biomolecules, resulting in cell death and tissue damage [1]. In recent years, there has been increasing evidence that reactive oxygen species (ROS) are associated with pathological conditions such as atherosclerosis [2] and carcinogenesis [3], as well as with aging [4]. Thus, a lot of attention has focused on dietary antioxidants which may have a potential for therapeutic use and prevention of these diseases. Investigations into the health maintaining properties of plants have resulted in the identification of a wide array of bioactive compounds in plants that include flavonoids, phenolics, limonoids, carotenoids, coumarins, phytosterols, etc. Based on recent research, several compounds from fruits and vegetables were found to possess anticarcinogenic and antioxidant activities [5]. Furthermore, flavonoids and 
carotenoids have also been shown to inhibit cancer cell proliferation in vitro [6]. Antioxidant activity by scavenging of reactive oxygen species is important in preventing potential damage to cellular components such as DNA, proteins, and lipids. In the course of screening for antioxidants in Thai medicinal plants, the methanol extract of the leaves of Guava showed a scavenging activity toward ABTS free radical decolorization assay and Ferric reducing power (FRAP) assay [7]. Guava (Psidium guajava L., Myrtaceae) leaves have been used in folk medicine of Thailand as an antidiarrheal [8] and antidysenteric; externally, they have been used as a deodorant of mouth odor [9]

The aim of this work was to determine the active principles from leaves of guava grown in Thailand, and to assess their antioxidant properties.

\section{Experimental}

\section{Materials and physicochemical study}

Melting points were determined on a Yanako melting point apparatus. IR spectra were recorded with a JASCO FT/IR-230 spectrophotometer. NMR spectra were recorded on a JEOL JNM- $\alpha 400$ spectrometer $\left(400 \mathrm{MHz}\right.$ for ${ }^{1} \mathrm{H}$ and $100 \mathrm{MHz}$ for ${ }^{13} \mathrm{C}$ ). Chemical shifts are shown as $\delta$ values, using tetramethylsilane (TMS) as an internal reference. Column chromatography was carried out on Cosmosil $75 \mu \mathrm{m}$ $\mathrm{C}_{18}$-OPN (Nacalai Tesque), Sephadex LH-20 (GE Healthcare Biosciences AB), Silica gel 60 (230-400 mesh) (Merck), Toyopearl-HW40C (Tosoh Co.) and MCl-gel CHP-20P (Mitsubishi Co.). TLC was performed on pre-coated RP-18 $F_{254}(0.25 \mathrm{~mm})$ 
(Merck), and spots were detected by UV $(254 \mathrm{~nm})$ and by $10 \% \mathrm{H}_{2} \mathrm{SO}_{4}$ spraying reagent followed by heating. Water was deionized and purified using a Milli-Q system (Millipore, Bedford, MA, USA). All other chemicals used were of the highest commercial grade available, purchased from Wako Pure Chemical Industries.

\section{Plant material}

The dried leaves of $P$. guajava were collected at Chiang Mai Province, Thailand. A voucher specimen is deposited in the herbarium, Faculty of Pharmacy, Chiang Mai University, Thailand.

\section{Extraction and isolation}

The dried leaves of $P$. guajava $(800 \mathrm{~g})$ were partitioned by successive extraction with $n$-hexane, EtOAc, $n$-butanol and $\mathrm{MeOH}$ to give $n$-hexane fraction $(15.0 \mathrm{~g}$ ), EtOAc fraction $(13.9 \mathrm{~g}), n$-butanol fraction $(11.9 \mathrm{~g})$ and $\mathrm{MeOH}$ fraction $(151.5 \mathrm{~g})$, respectively.

The antioxidant activity of the resulting fractions was determined by the use of the DPPH method. The highly active methanolic fraction $(20 \mathrm{~g})$ was subjected to silica gel column chromatography (Cosmosil $\mathrm{C}_{18}-\mathrm{OPN}, 75 \mu \mathrm{m}, 6.0 \mathrm{~cm}$ i.d. x $40 \mathrm{~cm}$ ) and eluted with $\mathrm{MeOH}$ of increasing polarities with water (5 to $100 \% \mathrm{MeOH}$ ). The volume of each collected fraction was $100 \mathrm{ml}$ to give 6 fractions (A, B, C, D, E, and F). High antioxidant activity was found in fraction C, D and E. The highly active fraction C (1.0 g) was re-chromatographed over a Sephadex LH-20 column (2.5 cm i.d. x 100 
$\mathrm{cm}$ ) with $\mathrm{MeOH}$, acetone: $\mathrm{MeOH}(1: 1)$ and acetone. The most active fraction obtained (48.8mg) was then subjected to silica gel column chromatography (Silica gel 60, 230-400 mesh, $1.0 \mathrm{~cm}$ i.d. $\times 20 \mathrm{~cm}$ ) and eluted with $n$-hexane:EtOAc, EtOAc, EtOAc:acetone, acetone and $\mathrm{MeOH}$ to yield compound 1 (14.9 $\mathrm{mg})$ from $n$-hexane:EtOAc (3:7) fraction.

Fraction D (1.804 g) was chromatographed over Toyopearl HW-40C (1.0 i.d.x70 $\mathrm{cm})$ with aqueous $\mathrm{MeOH}(5,10,20,30,50,70$, and $100 \%)$ and $70 \%$ aqueous acetone. The $10 \% \mathrm{MeOH}$ eluate $(61.90 \mathrm{mg})$ was separated to Cosmosil $75 \mu \mathrm{m}$ C18-OPN (1.0 i.d.x20 cm) and eluted with 5, 15, 25, 50, and 100\% $\mathrm{MeOH}$ to yield compound 2 (4.0 mg).

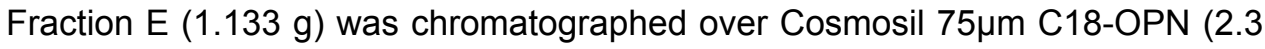
i.d. $\times 13 \mathrm{~cm}$ ) and eluted with $20,30,40,50$, and $100 \%$ ethanol. The $30 \%$ ethanol eluate $(691.30 \mathrm{mg})$ was re-chromatographed over Cosmosil $75 \mu \mathrm{m}$ C18-OPN (2.0 i.d.x12 cm) and eluted with $25,50,75$, and $100 \%$ ethanol. The $50 \%$ ethanol eluate (567.50 mg) was subjected to column chromatography over MCl-gel $(1.0$ i.d x $53 \mathrm{~cm}$ ) with $30,40,50,60$, and $100 \% \mathrm{MeOH}$ to give four factions. The second fraction (231 $\mathrm{mg}$ ) was re-chromatographed over Toyopearl HW-40C and eluted with 50, 53, 55, 57 , 60 , and $100 \% \mathrm{MeOH}$ and $70 \%$ acetone to yield compound 3 (33.7 mg).

\section{Free Radical-Scavenging Activity Assay}

DPPH radical scavenging is considered a good in vitro model and is widely used to conveniently assess antioxidant efficacy. In its radical form, DPPH free radical has 
an absorbance at $515 \mathrm{~nm}$ which disappears when DPPH is reduced by an antioxidant compound or a radical species to become a stable diamagnetic molecule. As a result, the color changes from purple to yellow [9]. This color change is taken as an indication of the hydrogen donating ability of the tested compounds.

The DPPH radical scavenging activity of the samples was estimated according to the methods of Brand-Williams et al., 1995 [9] and Gamez et al., 1998 [10] with some modification. Samples in $\mathrm{MeOH}(100 \mu \mathrm{l})$ were added to a solution of DPPH radical in $\mathrm{MeOH}(200 \mu \mathrm{M}, 100 \mu \mathrm{l})$, and the reaction mixture was left to stand for 30 min at room temperature in the dark. The scavenging activity of samples was estimated by measuring the absorption of the mixture at $515 \mathrm{~nm}$, which reflects the amount of DPPH radical remaining in the solution. The scavenging activity was expressed as the $\mathrm{IC}_{50}$, the concentration of samples required for scavenging $50 \%$ of DPPH radical in the solution.

\section{Results and Discussion}

Phenolic compounds are the major group that contributes to the antioxidant activity of vegetables, fruits, cereals and other plant based materials. In our previous work, different solvents were used for the extraction of phenolic compounds from guava leaves and we have reported [7] that a methanol extract gave high antioxidant activities from 24 samples of plant species commonly found in Thailand. Therefore, in the present study, the bioactive compounds from guava leaves were isolated and the chemical structures were identified. 
The dried leaves of $P$. guajava were extracted sequentially with $n$-hexane, EtOAc, $n$-butanol and $\mathrm{MeOH}$ in order to identify the fraction with the highest antioxidant activity. As reported previously, the methanolic fraction gave the highest scavenging activity. The methanolic fraction was then fractionated and purified according to the antioxidant test. The active purified principles were analyzed for their chemical structures by IR, ${ }^{13} \mathrm{C}-\mathrm{NMR},{ }^{1} \mathrm{H}-\mathrm{NMR}, \mathrm{MS}$ analyses and in comparison with the data of authentic quercetin [10-12], morin [13] and quercetin-3-O-glucopyranoside [14-15]. Results revealed the three active principles as compound $\mathbf{1}$, compound $\mathbf{2}$, and compound $\mathbf{3}$ as follows.

Compound 1 was obtained as a pale yellow powder of melting point $300^{\circ} \mathrm{C}$ (decomposed) and El-MS m/z: $302[\mathrm{M}]^{+}$. IR absorption band at 3293.82, 1616.06, 1511.92 and 1166.72 were consistent with the presence of hydroxyl, carbonyl, aromatic ring and ether groups respectively. The proton and carbon NMR of this compound were shown in Fig 1 and 2, respectively. The ${ }^{1} \mathrm{H}-\mathrm{NMR}\left(400 \mathrm{MHz}, \mathrm{CD}_{3} \mathrm{OD}\right)$ : ठ $6.17(1 \mathrm{H}, \mathrm{s}, \mathrm{H}-6), 6.37(1 \mathrm{H}, \mathrm{s}, \mathrm{H}-8), 6.86(1 \mathrm{H}, \mathrm{d}, \mathrm{J}=8.4, \mathrm{H}-5$ ') $7.62(1 \mathrm{H}, \mathrm{d}, \mathrm{J}=8.6$, H-6'), 7.72 (1H, s, H-2'). The ${ }^{13} \mathrm{C}-\mathrm{NMR}\left(100 \mathrm{MHz}, \mathrm{CD}_{3} \mathrm{OD}\right): \delta 94.58$ (C-8), 99.41 (C-6), 104.69 (C-10), 116.18 (C-2'), 116.39 (C-5'), 121.85 (C-6'), 124.32 (C-1'), 137.37 (C-3), 146.38 (C-3'), 148.19 (C-4'), 148.93 (C-2), 158.41 (C-9), 162.67 (C-5), 165.72 (C-7), 177.50 (C-4). From these results, compound 1 was considered quercetin and its chemical structure is shown in Fig 3. 


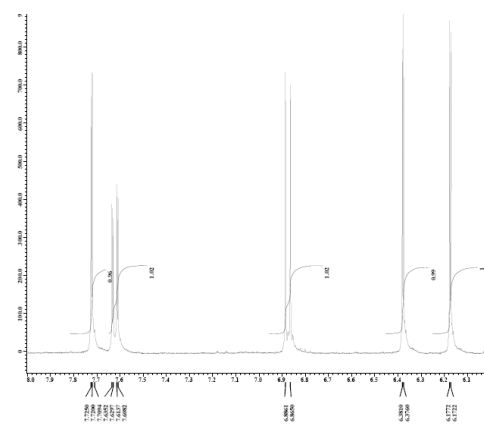

Fig. $1{ }^{1} \mathrm{H}$ NMR spectrum of compound 1

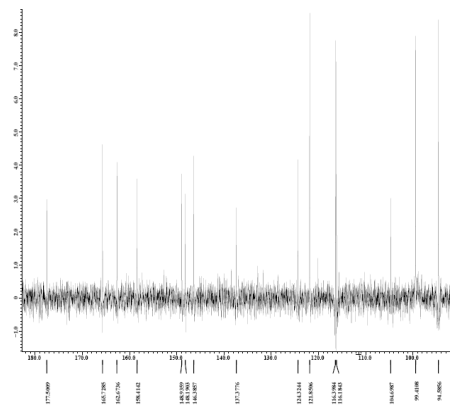

Fig. $2{ }^{13} \mathrm{C}$ NMR spectrum of compound 1<smiles>O=c1c(O)c(-c2ccc(O)c(O)c2)oc2cc(O)cc(O)c12</smiles>

Fig. 3 Chemical structure of compound 1

Compound 2 was obtained as a yellow powder of melting point $300^{\circ} \mathrm{C}$ (decomposed) and EI-MS m/z: $302[\mathrm{M}]^{+}$. IR absorption bands at 3484.74, 1604.48, 15263.15, 1052.94.were consistent with the presence of hydroxyl, carbonyl, aromatic ring and ether groups respectively. The proton and carbon NMR of this compound were shown in Fig 4 and 5, respectively. The ${ }^{1} \mathrm{H}-\mathrm{NMR}\left(400 \mathrm{MHz}, \mathrm{CD}_{3} \mathrm{OD}\right): \delta 6.19(1 \mathrm{H}$, s, H-6), $6.39(1 \mathrm{H}, \mathrm{s}, \mathrm{H}-8), 6.87\left(1 \mathrm{H}, \mathrm{d}, \mathrm{H}-5^{\prime}\right), 7.63\left(1 \mathrm{H}, \mathrm{d}, \mathrm{H}-6^{\prime}\right), 7.68\left(1 \mathrm{H}, \mathrm{s}, \mathrm{H}-3^{\prime}\right)$. The 
${ }^{13} \mathrm{C}-\mathrm{NMR}\left(100 \mathrm{MHz}, \mathrm{CD}_{3} \mathrm{OD}\right): \delta 93.41$ (C-8), 98.58 (C-6), 104.46 (C-10), 114.90 (C-3'), 115.84 (C-5'), 121.78 (C-6'), 121.94 (C-1'), 132.10 (C-3), 144.73 (C-2), 148.73 (C-4'), 157.02 (C-9), 158.02 (C-2'), 161.80 (C-5), 164.71 (C-7), 177.96 (C-4). From these results, compound 2 was considered morin and its chemical structure is shown in Fig 6.

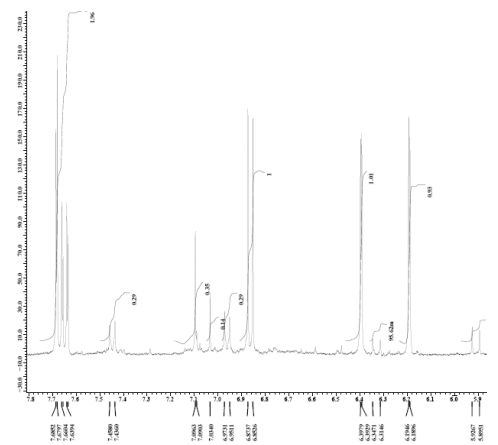

Fig. $4{ }^{1} \mathrm{H}$ NMR spectrum of compound 2

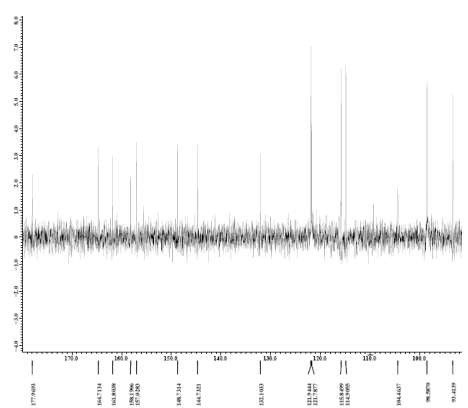

Fig. $5{ }^{13} \mathrm{C}$ NMR spectrum of compound 2<smiles>O=c1c(O)c(-c2ccc(O)cc2O)oc2cc(O)cc(O)c12</smiles>

Fig. 6 Chemical structure of compound 2 
Compound 3 was obtained as a yellow powder. It showed melting point at 220-225 ${ }^{\circ} \mathrm{C}$ and El-MS m/z: $464[\mathrm{M}]^{+} . \mathrm{IR}$ absorption bands at 3739.30, 1648.84, $1562.06,1492.63,1295.93,1054.87,622.89$ were consistent with the presence of hydroxyl, carbonyl, aromatic ring and ether groups respectively. The proton and carbon NMR of this compound were shown in Fig 7 and 8, respectively. The ${ }^{1} \mathrm{H}-\mathrm{NMR}$ (600MHz, $\left.\mathrm{CD}_{3} \mathrm{OD}\right):$ ס $3.42\left(1 \mathrm{H}, \mathrm{t}, 8.7, \mathrm{H}-5^{\prime \prime}\right), 3.48\left(1 \mathrm{H}, \mathrm{m}, \mathrm{H}-3^{\prime \prime}\right), 3.54\left(1 \mathrm{H}, \mathrm{m}, \mathrm{H}-6 \mathrm{a}^{\prime \prime}\right)$, 3.55 (1H, m, H-2"), 3.64 (1H, d, H-6b"), 3.85 (1H, m, H-4"'), 5.09 (1H, d, 7.70, H-1"), $6.13(1 \mathrm{H}, \mathrm{d}, 2.0, \mathrm{H}-6), 6.30(1 \mathrm{H}, \mathrm{d}, 2.0, \mathrm{H}-8), 6.86(1 \mathrm{H}, \mathrm{d}, 8.5, \mathrm{H}-5$ '), $7.58(1 \mathrm{H}, \mathrm{dd}, 8.5$, H-6'), 7.83 (1H, d, 2.2, H-2'). The ${ }^{13} \mathrm{C}-\mathrm{NMR}\left(150 \mathrm{MHz}, \mathrm{CD}_{3} \mathrm{OD}\right): \delta 60.59$ (C-6"), 68.68 (C-4"), 73.85 (C-2"), 75.82 (C-3"), 77.02 (C-5"), 94.26 (C-8), 99.85 (C-6), 103.18 (C-1")104.36 (C-10), 114.78 (C-5'), 116.34 (C-2'), 121.53 (C-6'), 121.79 (C-1'), 134.40 (C-3), 144.52 (C-3'), 148.68 (C-4'), 156.44 (C-2), 157.40 (C-9), 161.44 (C-5), 165.50 (C-7), 177.70 (C-4). From these results, compound 3 was considered quercetin-3-O-glucopyranoside and its chemical structure is shown in Fig 9.

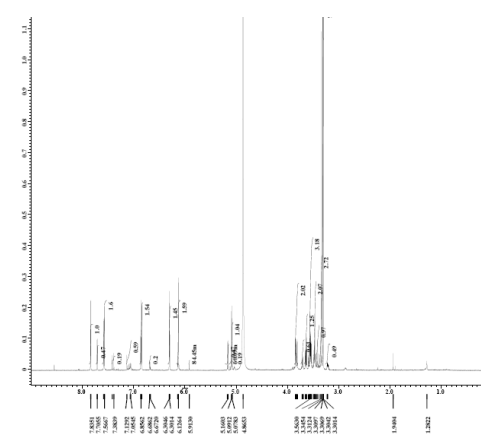

Fig. $7{ }^{1} \mathrm{H}$ NMR spectrum of compound 3

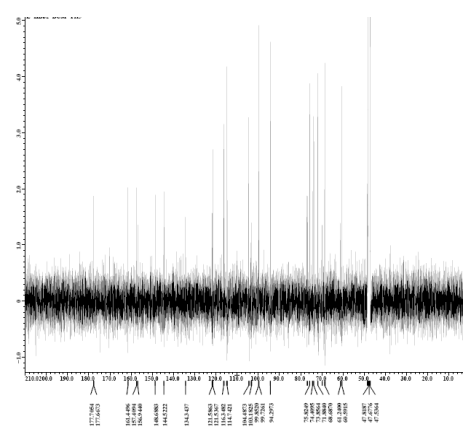

Fig. $8{ }^{13} \mathrm{C}$ NMR spectrum of compound 3 


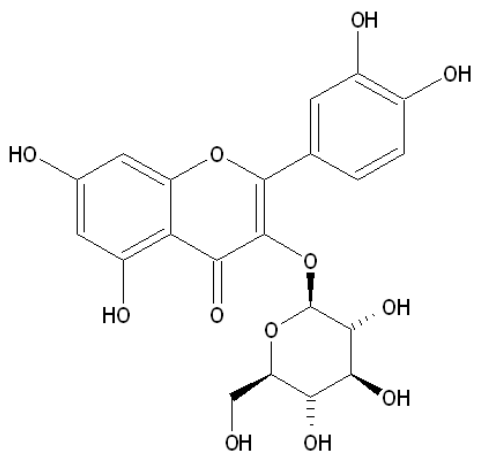

Fig. 9 Chemical structure of compound 3

Many attempts have been reported in the literature to delineate the structure-activity relationship underlying the natural antioxidant activity of certain phenolic compounds. This may involve the neutralization of free radicals initiating oxidation processes, or the termination of radical chain reactions, due to their hydrogen donating ability [16]. In this study, the comparative biological activity of three compounds isolated from guava leaves was evaluated as their antioxidant capacity to scavenge DPPH free radicals. It was found that all three isolated principles, quercetin, quercetin-3-O-glucopyranoside and morin had antioxidant activity but at different levels as shown in Fig 10 with the $\mathrm{IC}_{50}$ of $1.20 \pm 0.02,3.58 \pm 0.05$ and $5.41 \pm 0.20 \mu \mathrm{g} / \mathrm{ml}$, respectively. It was clearly seen that quercetin is the most active principle in Thai guava leaves, followed by quercetin-3-O-glucopyranoside and morin, respectively. This result could be explained by the higher antioxidant activity being related to the greater number of hydroxyl groups on the flavonoid nucleus. The antioxidant activity of flavonoids was considered dependent on the presence of ortho 
phenolic functions [17]. This finding is in accordance with the results reported by Bors et al., 1990 [18] and confirms that the O-dihydroxybenzene (catechol) structure is an important feature for enhanced radical-scavenging activity.

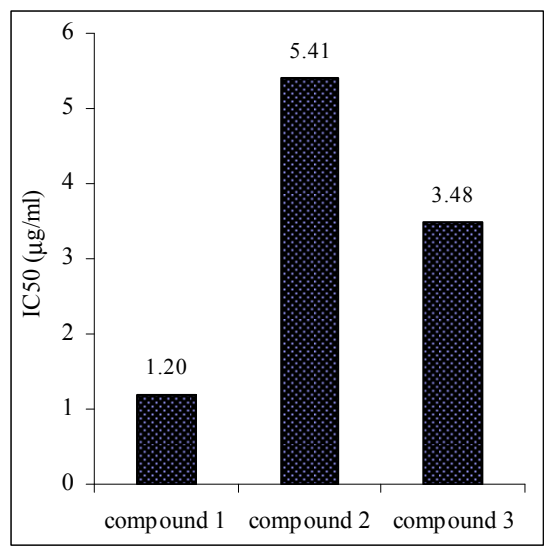

Fig. 10 The $\mathrm{IC}_{50}$ value $(\mu \mathrm{g} / \mathrm{ml})$ for the isolated compounds

\section{Conclusion}

The methanolic extract of Thai guava leaves has high antioxidant activity. The active principles isolated from the methanolic extracts are three flavonoids with different levels of antioxidant power. The structure elucidation study reveals that the three active principles are quercetin, quercetin-3-O-glucopyranoside and morin

\section{Acknowledgement}

The authors are grateful for the financial support of the RGJ Grant and the DBR-MC Grant awarded by the Thailand Research Fund. 


\section{References}

[1] Halliwell B, Gutteridge JMC.

Free Radicals in Biology and Medicine.

Oxford University press, Oxford: UK, 2003.

[2] Patel RP, Moellering D, Murphy-Ullrich J, Jo H, Beckman JS, Darley-Usmar VM.

Cell Signaling by Reactive Nitrogen and Oxygen Species in Atherosclerosis. Free Radical Biology and Medicine 2000; 28 (12): 1780-1794.

[3] Emerit I.

Reactive Oxygen Species, Chromosome Mutation, and Cancer: Possible Role of Clastogenic Factors in Carcinogenesis.

Free Radical \& Medicine 1994; 16: 99-109.

[4] Hipkiss AR.

Accumulation of Altered Proteins and Ageing: Cause and Effects.

Experimental Gerontology 2006; 41: 464-473.

[5] Okonogi S, Duangrat C, Anuchpreeda S, Tachakittirungrod S, Chowwanapoonpohn S.

Comparison of antioxidant capacities and cytotoxicities of certain fruit peels. Food Chemistry 2007; 103(3): 839-846.

[6] Prakash P, Russel RM, Krinsky NI.

In Vitro Inhibition of Proliferation of Estrogen-Dependent and

Estrogen-Independent Human Breast Cancer Cells Treated with Carotenoids or Retinoids.

Journal of Nutrition 2001; 131: 1574-1580.

[7] Tachakittirungrod S, Okonogi S, Chowwanapoonpohn S.

Study on Antioxidant Activity of Certain Plants in Thailand: Mechanism of Antioxidant Action of Guava Leaf Extract.

Food Chemistry 2007; 103: 381-388.

[8] Lutterodt G.D

Inhibition of Gastrointestinal Release of Acetylcholine by Quercetin as a Possible Mode of Action of Psidium Guajava Leaf Extracts in the Treatment of Acute Diarrhoeal Disease.

Journal of Ethnopharmacology 1989; 25: 235-247. 
[9] Brand-Williams W, Cuvelier ME, Berset C.

Use of a Free Radical Method to Evaluate Antioxidant Activity.

Food Science and Technology 1995; 28(1): 25-30.

[10] Gamez EJC, Luyengi L, Lee SK, Zhu LF, Zhou BN, Fong HHS, Pezzuto JM, Kinghorn, A.D.

Antioxidant Flavonoid Glycosides from Daphniphyllum Calycinum.

Journal of Natural Products 1995; 61(5): 706-708.

[11] Arima H, Danno G.

Isolation of Antimicrobial Compounds from Guava (Psidium guajava L.) and their Structural Elucidation.

Biosci. Biotechnol. Biochem 2002; 66 (8): 1727-1730.

[12\} Ternai B, Markham KR.

Carbon-13 NMR Studies of Flavonoids-I Flavones and Flavonols.

Tetrahedron 1976; 32: 565-569.

[13] Markham KR, Ternai B, Stanley R, Geiger H, Mabry TJ.

Carbon-13 NMR studies of Flavonoids-III Naturally Occurring Flavonoid Glycosides and their Acylated Derivatives.

Tetrahedron 1978; 34: 1389-1397.

[14] Slimestad R, Torskangerpoll K, Nateland HS, Johannessen T, Giske NH.

Flavonoids from Black Chokeberries., Aronia Melanocarpa.

Journal of Food Composition and Analysis 2005; 18: 61-68.

[15] Baumann J, Wurn G, Bruchalausen FV.

Prostaglandin Synthetase Inhibiting $\mathrm{O}_{2}$-Radical Scavenging Properties of Some Flavonoids and Related Phenolic Compounds.

Naunyn-Schmiedebergs Archives of Pharmacology 1979; 308: R27.

[16] Cao G, Sofic E, Prior RL.

Antioxidant and Prooxidant Behaviour of Flavonoids: Structure-Activity

Relationships.

Free Radical Biology and Medicine 1997; 22: 749-760. 
[17] Foti M, Piattelli M, Baratta MT, Ruberto G.

Flavonoids, Coumarins, and Cinnamic Acids as Antioxidants in a Micellar System. Structure-Activity Relationship.

Journal of Agricultural and Food Chemistry 1996; 44: 497-501.

[18] Bors W, Heller W, Michel C, Saran M.

Flavonoids as Antioxidants: Determination of Radical-Scavenging Efficiencies.

In L. Packer (Ed.), Methods in Enzymology. Vol. 335.

San Diego, CA: Academic Press, 1990: 343-355. 